'T left dental nursing to become an HGV driver'

BDJ Team's features on dental nurse wages caused a storm on our Facebook page in 2016. Salary is a topic that is close to many dental nurses' hearts. Here we present a selection of comments made by DCPs on our Facebook posts during the course of last year. If you didn't see the original BDJ Team content on dental nurse wages, links are included at the end of this article.
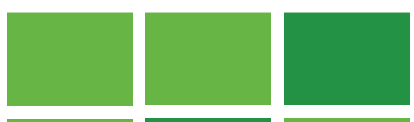

'Love the job. Hate the pay. All other dental professionals receive higher salaries. Dentists can't practise without us therefore we should be paid accordingly'. Janet

'It's sad we don't get paid more. I don't expect millions but we work hard to qualify. We train all year round to keep up to date with CPD to stay registered. (We are just as responsible for the patients' welfare as dentists in the eyes of the GDC.) We're trained in CPR.

The dentist cannot work without us. In most cases it's the nurse who keeps the surgeries running. And yet we get paid poorly; in my case it's pence over living wage. But to think I could get a job where I don't need any qualifications and be paid more is ridiculous.'

Lauren

\title{
'Dentists can't
}

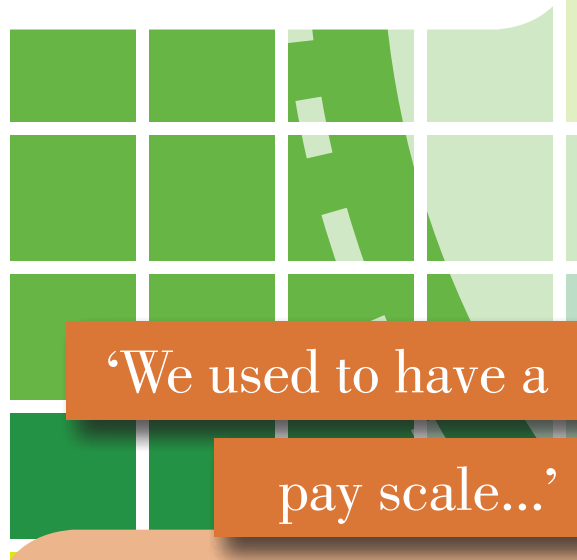

'I love being a dental nurse, have done for years, but it's true we are underpaid. I get paid $1 \mathrm{p}$ above living wage. I have a total of 15 years' experience. I work part time - well 3/4 time as have young family, so I earn below the tax band. So when I pay my registration I cannot claim it back. Put it on my tax code ... therefore I work out I get paid under living wage.

The reason I'm still there is because one, I love what I do, two, it's near where I live, and finally three it's better the devil you know I think.'

Sarah

'Wages will have to change or all qualified nurses will just work for agencies; in the old days we had the Whitley scale - pay depended on experience and qualifications - it was a much fairer system and it was black and white.'

Sue

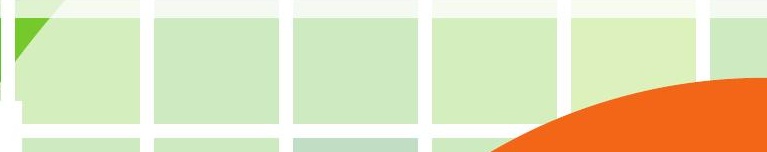

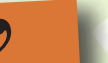

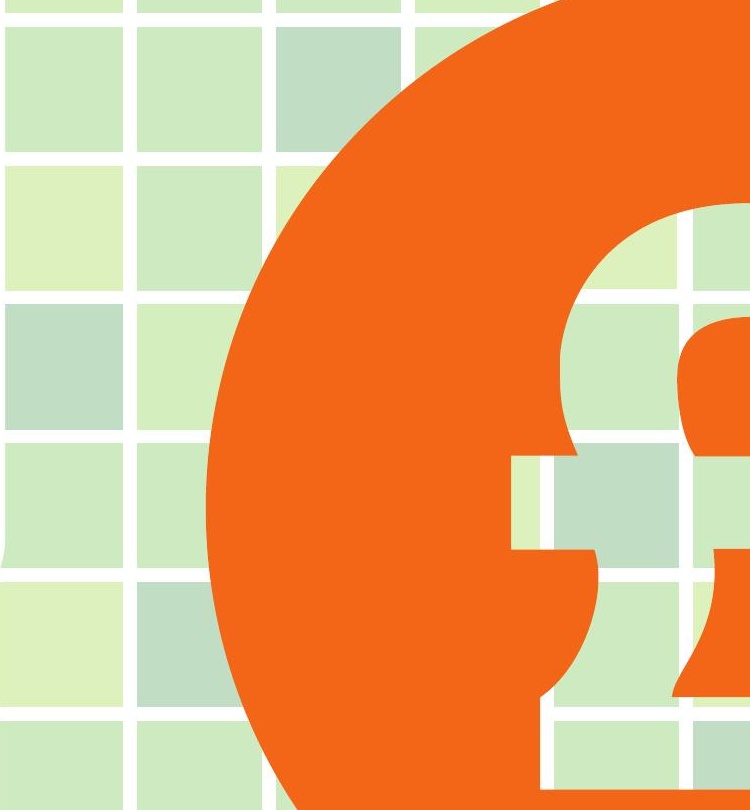

'I'm sorry, why are receptionists earning more than qualified registered professionals? Most nurses end up doing a lot of reception work as well as nursing so why exactly are we training, taking exams, paying registration, keeping updated on $\mathrm{CPD}$, and working our backsides off for less money than the rest of the team? It's absolutely disgraceful!'

Jodie

'As said above we used to have a pay scale, that was BEFORE registration, CPD, CQC etc ... now there is nothing even though we are 'professionals'. I haven't had a pay rise for four years ... guess what, my rent alone has more than doubled in that time. I'm poorer than I was as my wages are the same ... they can't stretch much further! Oh but the fees for a large composite filling have gone from $£ 95$ to $£ 140$, not bad for 40 minutes' work!' Verne 
'Very disheartened and disgruntled that dental nurse wage is what it is. I believe it should be banded just like hospitals and community. Thriving practices need to realise they are thriving because of the TEAM behind them and need to pay accordingly. I know of dental nurses that are paid less than their reception colleagues even though they now have outlays such as indemnity. I have often thought about throwing the towel in and going to work for a supermarket that pays better but I love my job and the people I work closely with so I just keep doing what I do.' Amy
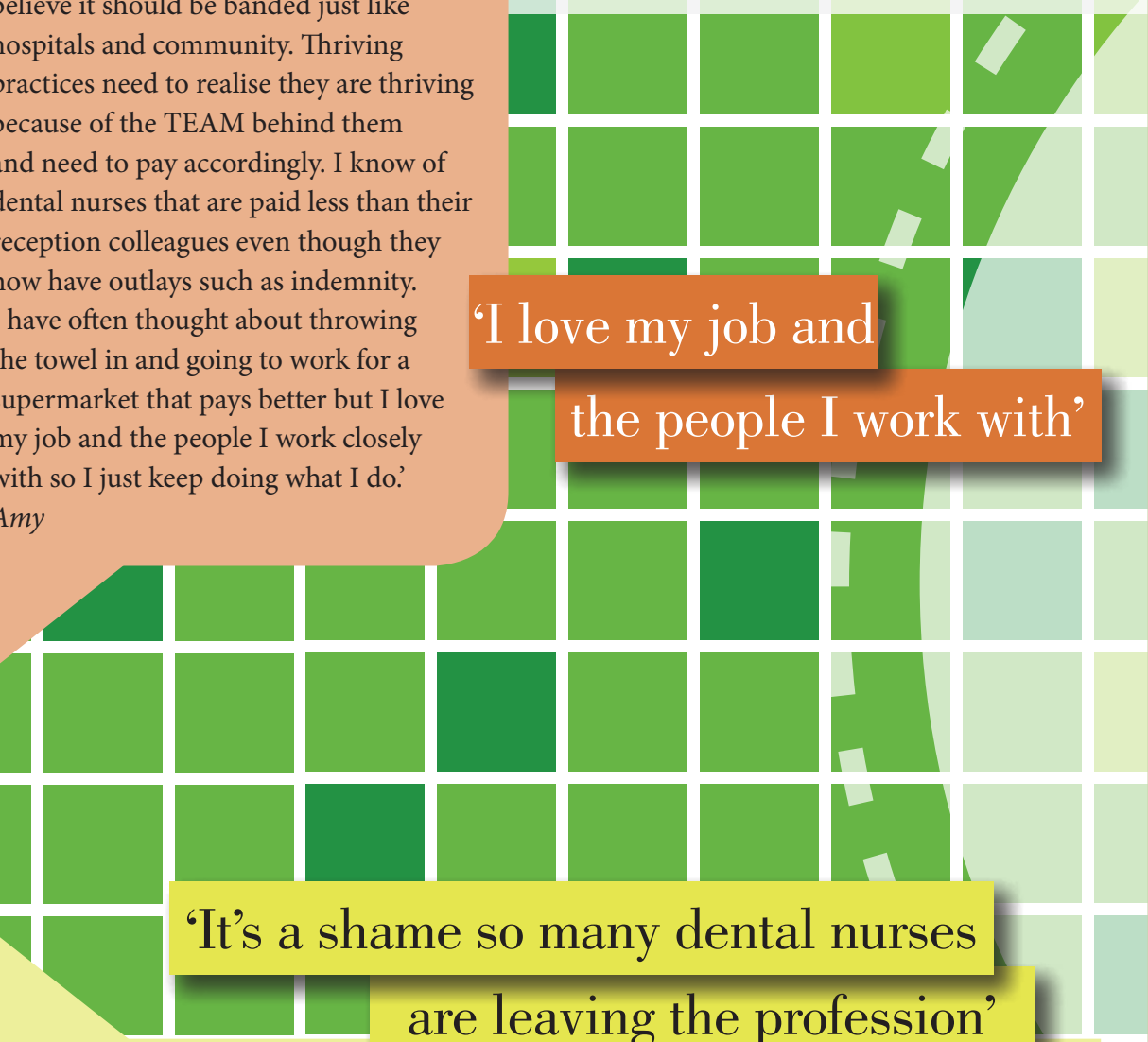

\section{'It's a shame so many dental nurses}

\section{are leaving the profession'}

'I think it's a shame as so many dental nurses are leaving the profession for an easy life/job in retail etc without any $\mathrm{CPD}$ requirements and where they can go in and out of work without any other attachment/responsibility. Unfortunately for those of us with many years' experience and further qualifications the pay is not reflected accordingly. When I qualified in 2003 and moved into my first job, the pay was more than acceptable but fast forward 13 years ( 15 since I began in this career) radiography, FV application, progressing with sedation nursing and extra responsibilities that have naturally fallen upon us all with multiple changes to our role in this time and actually just over $£ 2$ pay increase in 13 years... then something has to be done. We do have responsibilities and we do have an element of liability in the increasing litigious culture we live in. Bring back the Whitley scale and get us all earning what we rightly deserve. The onus is entirely on the practice owner which I I have been there) have empathetic bosses that appreciate what we do but I think more reward is required from higher up. The NHS certainly should provide those of us in NHS practice with an NHS pension if nothing else. I am very passionate about the job I do and want to better myself at every opportunity; however the adverts in Aldi offering very good pay are sometimes a temptation.' Amy

'I've literally just finished training as a dental nurse and it's my biggest regret now realising the shoddy pay scale. It's so insulting to have to put so much hard work into something and get minimum wage while you run around for dentists earning a bomb! Looking to stop it already unfortunately, which is a shame because I love the actual job.' Kaye
'I'm a part-owner of a practice and my main role is managing the business aspects and developing the team. As I came from a non-dental background, I'm training as a dental nurse just now. Our practice is based in central Scotland and is mixed NHS/ private. We contribute towards our team ARF and help to provide some of their $\mathrm{CPD}$ with pensions on the way.

My question is, what would you (as dental nurses) genuinely see as a 'fair' hourly rate? I find this quite difficult as the costs of running a practice are constantly increasing and it's proving harder and harder, particularly under NHS, to be sustainable. I can, therefore, see both sides of the argument here.

Having taken on the role of the dental nurse myself (purely to understand and know how it feels!) I fully appreciate everything nurses contribute but no-one (dental nurses I've spoken to about it) can tell me what they think would be a "fair wage".

Regardless of which jobs I've been in previously, I find that people always want more money (naturally) but they often find it hard to quantify and justify. I think that's actually quite an important aspect here.

It's definitely interesting to see the differences in how practices utilise, treat and pay their staff ... often, finding a great environment also helps tip the balance - a bit of appreciation goes a long way for a dental nurse!' Linsey

\section{Relevant BDJ Team content}

Dental nurses are paid no more than shop assistants

http://www.nature.com/articles/ bdjteam2016115

Why are dental nurse salaries so low? http://www.nature.com/articles/ bdjteam2016152 the progress dental nurses have made http://www.nature.com/articles/ bdjteam2016162

\section{JOIN THE CONVERSATION!}

BDJ Team Facebook page: www.facebook.com/bdjteam
The profession does not acknowledge 